\title{
Characterization of the Kentville Stock Clone Apple Rootstocks. II. Precocity and Productivity
}

\author{
B.H. Lesser ${ }^{1}$, C.G. Embree ${ }^{2}$, and A.D. Crowe ${ }^{3}$ \\ Research Station, Agriculture Canada, Kentville, N.S., B4N 1J5, Canada \\ Additional index words. Malus domestica, rootstocks, precocity, yield curve
}

\begin{abstract}
The precocity and productivity of 30 Kentville Stock Clone (KSC) apple (Malus domestica Borkh.) rootstocks, with 'McIntosh' and 'Delicious' as scion cultivars, were assessed independently of each other using a procedure involving computer-aided fitting of curves to yearly production data. A good fit to the data was obtained after biennial fluctuations in yield were removed by using a weighted, 3-year running average. For all 30 rootstocks combined, 'McIntosh' was more precocious and reached a higher level of productivity compared to 'Delicious'. There was poor correlation between precocity and productivity.
\end{abstract}

Precocity and productivity are extensively studied characteristics of candidate apple rootstocks (Cummins and Aldwinckle, 1983). Before the selection of superior individuals, these traits, which are time dependent, often require years of evaluation to determine the degree of precocity and the level of productivity. Preston (1967) concluded that a 15-year field trial was required before rootstock performance could be defined fully, but preliminary selection could be made after 6 or 7 years. Crowe (1975) noted that the relative cropping advantage of MM.106 declined relative to other stocks after the early years, and he became concerned that selection based on precocity alone could be biased. Schmidt (1988) confirmed this concern, noting that the shorter the period of cumulative yields the greater the advantage of the precocityinducing M.9. Cummins and Aldwinkle (1983) also noted that clear distinctions are needed among aspects of precocity and productivity. The most common method of assessing productivity has been to measure fruit yield over a particular time span and adjust it for trunk circumference (Waring, 1920), tree weight (Pearce, 1952), or trunk cross-sectional area (TCA) (Westwood and Roberts, 1970). The latter is relatively easy to measure and is now the characteristic most widely used to describe efficiency. Unfortunately, when this method is used for numerous rootstocks for many years, it is very difficult to identify the most efficient because they could change positions each year. Efficiency in our view should reflect both the speed at which a tree comes into production (precocity) and the level of production it achieves and maintains when mature (productivity). Precocity is important, especially in high density orchards, but it may not signal superior productivity. When evaluating cultivars or rootstocks that vary in the rate at which they come into production, the selection of an appropriate time period on which to base the final conclusion becomes somewhat arbitrary. Dwarf rootstocks that have been selected for precocity will tend to be more efficient when a relatively short time span is chosen. More vigorous rootstocks likely will show higher levels of efficiency if a longer period is selected. It would be useful, therefore, to have a less time dependent method of assessing rootstock productivity. The purpose of this study was to compare the precocity and productivity of the 30

Received for publication 6 Jan. 1992. Accepted for publication 25 Aug. 1992. Kentville Station Publication no. 2109. The cost of publishing this paper was defrayed in part by the payment of page charges. Under postal regulations, this paper therefore must be hereby marked advertisement solely to indicate this fact. ${ }^{1}$ Research Scientist, term appointment.

${ }^{2}$ Research Scientist.

${ }^{3}$ Research Scientist, retired.
KSC rootstocks with 'McIntosh' and 'Delicious' as the scion cultivars. A method for determining rootstock precocity and productivity independently of each other is proposed and used in the comparison.

\section{Materials and Methods}

The selection and growth of the KSC rootstocks have been described by Embree and Crowe (1986).

All statistical analyses were made using Genstat 5 procedures (Genstat Committee, 1987). From each year's measurement of fruit yield and TCA for each tree, the crop load (CL) was calculated as kilograms of fruit per square centimeter TCA. The term "crop load" refers to each year's yield relative to that year's TCA, as opposed to "efficiency," which refers to the cumulative yield to that year relative to that year's TCA. To remove fluctuations in yield due to biennial bearing, an adjusted crop load (ACL) was calculated for each year using a 3-year running average weighted $50 \%$ to the current year and $25 \%$ each to the previous and following years, that is, $\mathrm{ACL}=\left(\mathrm{CL}_{\text {previous }}+2 \mathrm{CL}_{\text {current }}+\mathrm{CL}_{\text {following }}\right) / 4$. For the final year. ACL was the mean of $\mathrm{CL}$ that year and for the previous year. Logistic curves of the form ACL $=\mathrm{C} /\left[1+\mathrm{e}^{-\mathrm{B}}\left({ }^{\mathrm{Age}-\mathrm{M}}\right)\right]$ were fitted to the means for each cultivar/rootstock combination and the parameters $\mathrm{C}, \mathrm{B}$, and $\mathrm{M}$ were calculated. Age of the trees was in years. This method allows determination of: 1) the age when production begins, 2) the rate of increase, 3) time to half maximum cropping, and 4) maximum crop load.

\section{Results and Discussion}

Measurement of precocity and productivity. The methods of computer curve fitting and the correction for biennial bearing are illustrated in Fig. 1. The data shown are means for all 30 rootstocks with either 'McIntosh' (Fig. la) or 'Delicious' (Fig. lb) as scion. In the measured crop loads, there was a considerable degree of bienniality after the 6th year. Most of these fluctuations were removed by the adjustment based on a running 3-year average. The nature of the adjustment is such that there would be no effect on values that were changing linearly; before the 6th year, when there was a steady increase in crop load, the adjustment had only a small effect. The fit of the curves to the data accounted for $>98 \%$ of the variability in the data. The crop load approached a maximum equal

Abbreviations: ACL, adjusted crop load; CL, crop load; KSC, Kentville Stock Clone; TCA, trunk cross-sectional area. 

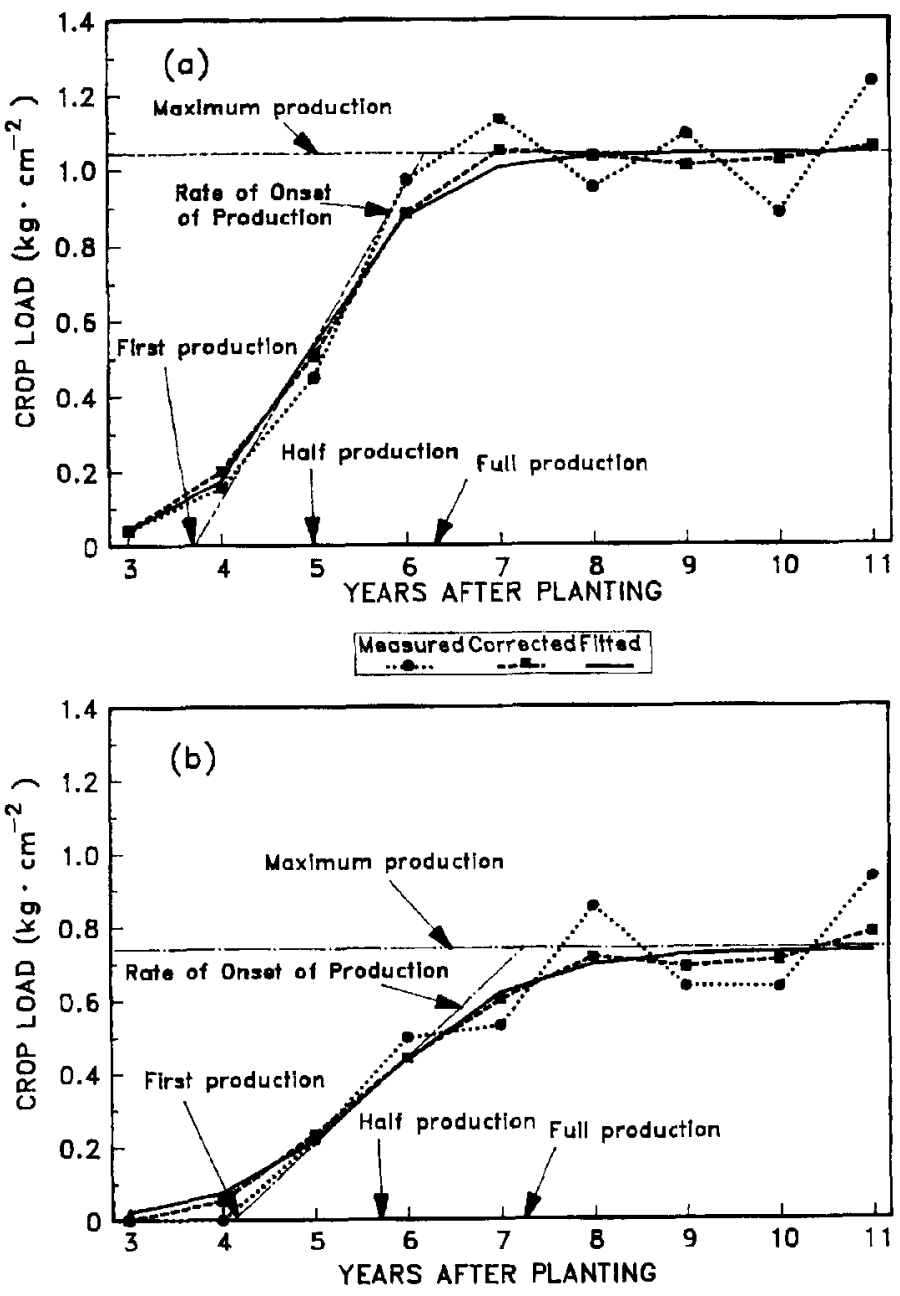

Fig. 1. CL as a function of tree age for (a) 'McIntosh' and (b) 'Delicious'. CL was calculated for each year as kilograms fruit per square centimeter TCA and shown as the mean for all trees of each cultivar. Adjusted CL was calculated as a 3-year running average of crop load, and curves were fitted to the equation $\mathrm{ACL}=\mathrm{C} /[1$

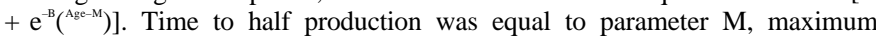
production to parameter $\mathrm{C}$, rate of onset of production to $\mathrm{C} \times \mathrm{B} / 4$, time to first production to $M-2 / B$, and time to full production to $M+2 / B$.

to the parameter $\mathrm{C}\left(1.05 \mathrm{~kg} \cdot \mathrm{cm}^{-2}\right.$ and $0.74 \mathrm{~kg} \cdot \mathrm{cm}^{-2}$ for 'McIntosh' and 'Delicious', respectively). At the inflection point of the curves, where crop load is half the maximum, age corresponds to the time to reach half production. At this point, the value of age is equal to the parameter M (5.0 years and 5.8 years for 'McIntosh' and 'Delicious', respectively). Also, the slope at the inflection point is at its maximal value and is equal to $\mathrm{C} \times \mathrm{B} / 4\left(0.43 \mathrm{~kg} \cdot \mathrm{cm}^{-2} \mathrm{year}^{-1}\right.$ and $0.24 \mathrm{~kg} \cdot \mathrm{cm}^{-2} \cdot \mathrm{year}^{-1}$ for 'McIntosh' and 'Delicious', respectively). These values can be considered to represent the rate of onset of production. The points at which the slope through the inflection point crosses the $\mathrm{X}$-axis and the asymptote represent the times to first production and full production, respectively, and can be calculated as $M+2 / B$ and $M-2 / B$, respectively. This method allows determinations of precocity and productivity that are consistent because they are based on the individual characteristics of each cultivar/rootstock combination, and they are accurate because they are based on multiple years of data from which fluctuations due to bienniality have been removed.

Precocity and productivity of each cultivar rootstock combination. The variability among some of the $30 \mathrm{KSC}$ rootstocks is illustrated for 'McIntosh' (Fig. 2a) and 'Delicious' (Fig. 2b)
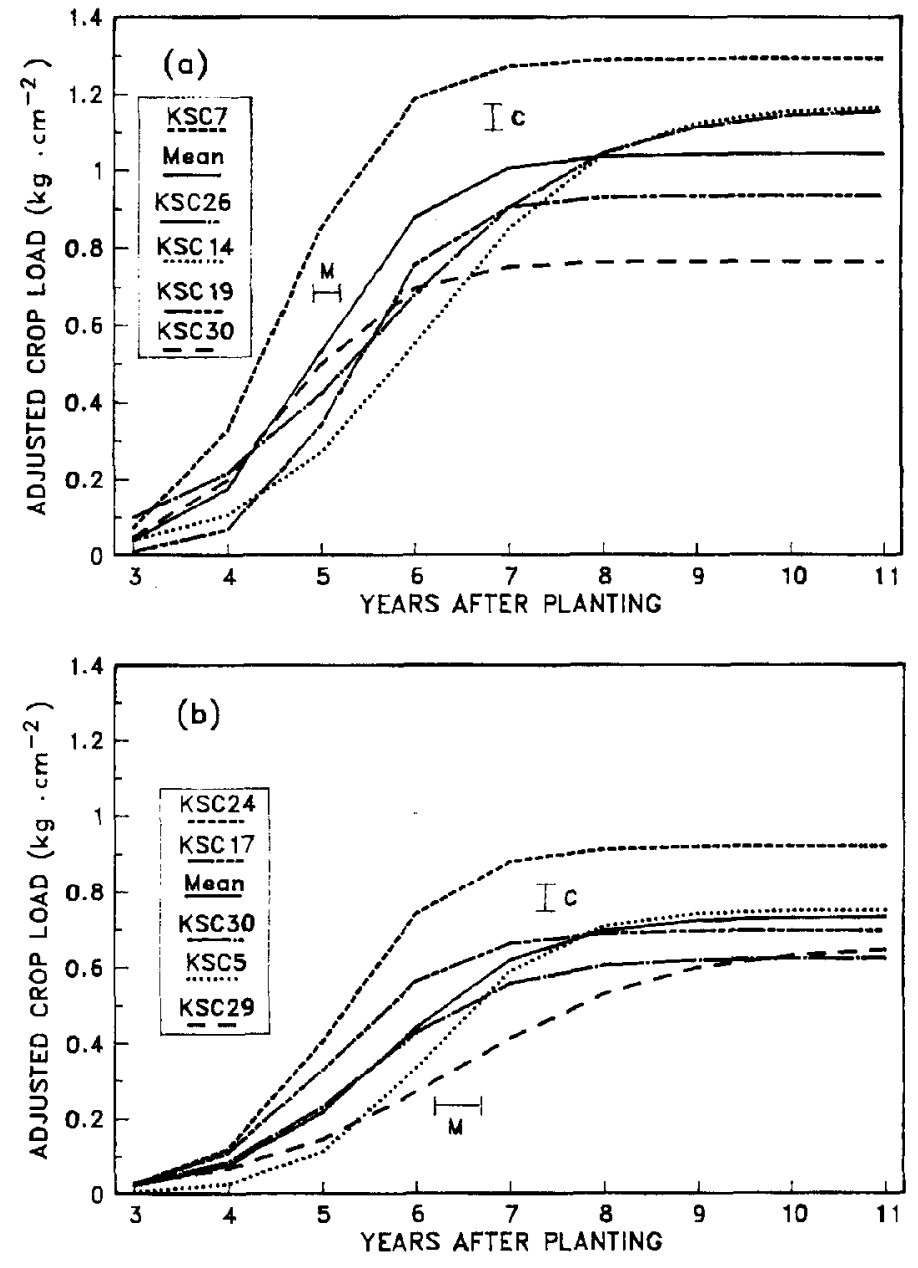

Fig. 2. Adjusted CL as a function of tree age for selected rootstocks with (a) 'McIntosh' and (b) 'Delicious' as scion. The error bars indicate the least significant difference at $P=0.05$ for the parameters $\mathrm{M}$ and $\mathrm{C}$.

scions. Some rootstocks (KSC 7 with 'McIntosh' and KSC 24 with 'Delicious') came into production sooner than the mean for all 30 rootstocks and reached a higher level of maximum productivity. Others (KSC 19 with 'McIntosh' and KSC 29 with 'Delicious') were slower than average in coming into production and never achieved the average level of maximum productivity. KSC 26 and KSC 14 with 'McIntosh' and KSC 5 with 'Delicious' all came into production later than average yet reached or exceeded the average maximum productivity. KSC 17 with 'Delicious' came into production earlier than average, but reached only average maximum productivity. KSC 30 with both cultivars was average in the rate at which it came into production, but inferior in its maximum productivity.

The time to first, half, and full production; rate of onset of production; and maximal production for 'McIntosh' and 'Delicious' on each of the $30 \mathrm{KSC}$ rootstocks, in order of increasing average TCA, are shown in Table 1. There was no obvious trend in any of the characteristics as tree size increased. There were significant rootstock and cultivar effects $(P<0.05)$ on all parameters.

The time to first production generated by this analysis was related, but not identical, to time of first production derived from fitting of efficiency data (Embree et al., 1993). This analysis provides a more accurate estimate of time to first production, since in the fitting of efficiency data less weight is given to early 
Table 1. Parameters derived from fitting of curves to yearly adjusted apple crop load data for each cultivar/KSC rootstock combination in order of increasing average tree size. Prod $=$ production.

\begin{tabular}{|c|c|c|c|c|c|c|c|c|c|c|}
\hline \multirow[b]{3}{*}{$\begin{array}{l}\text { KSC } \\
\text { (no.) }\end{array}$} & \multicolumn{5}{|c|}{ McIntosh } & \multicolumn{5}{|c|}{ Delicious } \\
\hline & \multicolumn{3}{|c|}{ Years to } & \multirow{2}{*}{$\begin{array}{c}\text { Rate of } \\
\text { onset } \\
\text { of prod }\end{array}$} & \multirow{2}{*}{$\begin{array}{c}\text { Maximum } \\
\text { prod } \\
\left(\mathrm{kg} \cdot \mathrm{cm}^{-2}\right)\end{array}$} & \multicolumn{3}{|c|}{ Years to } & \multirow{2}{*}{$\begin{array}{c}\text { Rate of } \\
\text { onset } \\
\text { of prod }\end{array}$} & \multirow{2}{*}{$\begin{array}{c}\text { Maximum } \\
\text { prod } \\
\left(\mathrm{kg} \cdot \mathrm{cm}^{-2}\right)\end{array}$} \\
\hline & $\begin{array}{l}\text { First } \\
\text { prod }\end{array}$ & $\begin{array}{l}\text { Half } \\
\text { prod }\end{array}$ & $\begin{array}{l}\text { Full } \\
\text { prod }\end{array}$ & & & $\begin{array}{l}\text { First } \\
\text { prod }\end{array}$ & $\begin{array}{l}\text { Half } \\
\text { prod }\end{array}$ & $\begin{array}{l}\text { Full } \\
\text { prod }\end{array}$ & & \\
\hline 28 & 2.8 & 4.3 & 6.0 & 0.32 & 1.01 & 3.8 & 5.0 & 6.2 & 0.36 & 0.84 \\
\hline 14 & 4.3 & 6.1 & 8.0 & 0.32 & 1.17 & 4.6 & 6.5 & 8.4 & 0.19 & 0.71 \\
\hline 26 & 3.4 & 5.6 & 7.8 & 0.26 & 1.17 & 4.3 & 5.9 & 7.5 & 0.22 & 0.69 \\
\hline 18 & 3.4 & 5.2 & 6.9 & 0.31 & 1.11 & 3.8 & 5.6 & 7.3 & 0.24 & 0.85 \\
\hline 23 & 4.0 & 5.3 & 6.6 & 0.41 & 1.07 & 4.1 & 5.8 & 7.6 & 0.21 & 0.75 \\
\hline 16 & 4.5 & 5.5 & 6.4 & 0.61 & 1.18 & 4.3 & 6.0 & 7.7 & 0.26 & 0.90 \\
\hline 4 & 3.8 & 4.9 & 6.0 & 0.48 & 1.10 & 3.9 & 5.8 & 7.8 & 0.19 & 0.72 \\
\hline 22 & 3.8 & 5.2 & 6.5 & 0.39 & 1.07 & 4.3 & 6.2 & 8.1 & 0.19 & 0.72 \\
\hline 24 & 3.5 & 4.8 & 6.2 & 0.39 & 1.03 & 3.9 & 5.2 & 6.4 & 0.38 & 0.92 \\
\hline 7 & 3.5 & 4.6 & 5.8 & 0.57 & 1.29 & 4.1 & 5.5 & 6.9 & 0.30 & 0.85 \\
\hline 19 & 4.3 & 5.3 & 6.3 & 0.47 & 0.94 & 4.4 & 6.0 & 7.7 & 0.21 & 0.68 \\
\hline 15 & 3.5 & 4.7 & 5.9 & 0.43 & 1.02 & 4.3 & 5.8 & 7.4 & 0.28 & 0.86 \\
\hline 9 & 4.3 & 5.6 & 6.9 & 0.42 & 1.10 & 4.4 & 5.7 & 7.0 & 0.25 & 0.66 \\
\hline 11 & 3.2 & 4.5 & 5.7 & 0.43 & 1.07 & 4.0 & 5.3 & 6.6 & 0.36 & 0.91 \\
\hline 25 & 3.4 & 4.8 & 6.2 & 0.38 & 1.05 & 4.0 & 5.3 & 6.6 & 0.25 & 0.66 \\
\hline 8 & 4.0 & 5.2 & 6.4 & 0.38 & 0.93 & 4.3 & 5.6 & 6.9 & 0.26 & 0.66 \\
\hline 29 & 3.9 & 5.3 & 6.8 & 0.36 & 1.04 & 4.2 & 6.4 & 8.7 & 0.15 & 0.66 \\
\hline 30 & 3.4 & 4.6 & 5.8 & 0.32 & 0.77 & 3.9 & 5.4 & 6.9 & 0.21 & 0.63 \\
\hline 12 & 3.8 & 4.9 & 6.0 & 0.47 & 1.03 & 4.4 & 5.6 & 6.8 & 0.31 & 0.75 \\
\hline 21 & 3.9 & 5.0 & 6.0 & 0.50 & 1.06 & 4.1 & 5.5 & 6.8 & 0.26 & 0.68 \\
\hline 13 & 4.0 & 5.0 & 6.1 & 0.52 & 1.09 & 4.2 & 5.5 & 6.9 & 0.28 & 0.75 \\
\hline 27 & 4.0 & 5.2 & 6.4 & 0.42 & 1.02 & 4.1 & 5.9 & 7.8 & 0.16 & 0.60 \\
\hline 20 & 4.3 & 5.1 & 6.0 & 0.53 & 0.92 & 4.5 & 6.6 & 8.7 & 0.17 & 0.70 \\
\hline 10 & 3.6 & 4.7 & 5.9 & 0.41 & 0.94 & 4.3 & 6.0 & 7.6 & 0.21 & 0.69 \\
\hline 17 & 4.0 & 5.0 & 6.0 & 0.52 & 1.04 & 3.8 & 5.1 & 6.4 & 0.27 & 0.70 \\
\hline 3 & 3.2 & 4.4 & 5.6 & 0.48 & 1.13 & 4.1 & 5.5 & 6.8 & 0.26 & 0.68 \\
\hline 1 & 3.5 & 4.9 & 6.3 & 0.38 & 1.09 & 4.0 & 6.5 & 9.0 & 0.15 & 0.76 \\
\hline 6 & 3.8 & 4.8 & 5.8 & 0.62 & 1.21 & 4.2 & 5.9 & 7.6 & 0.26 & 0.88 \\
\hline 5 & 4.0 & 4.8 & 5.6 & 0.61 & 1.01 & 4.8 & 6.2 & 7.5 & 0.28 & 0.75 \\
\hline 2 & 4.1 & 5.2 & 6.3 & 0.44 & 0.97 & 4.2 & 5.9 & 7.7 & 0.19 & 0.66 \\
\hline Mean & 3.8 & 5.0 & 6.3 & 0.44 & 1.05 & 4.2 & 5.8 & 7.4 & 0.24 & 0.74 \\
\hline SEM & 0.22 & 0.11 & 0.25 & 0.079 & 0.027 & 0.31 & 0.17 & 0.42 & 0.035 & 0.028 \\
\hline
\end{tabular}

Table 2. Correlation of apple precocity and productivity variables. Correlation coefficients were calculated for parameters derived from fitting of curves to adjusted CL data for each rootstock-cultivar combination.

\begin{tabular}{llc}
\hline & \multicolumn{2}{c}{ Coefficient of correlation } \\
\cline { 2 - 3 } Comparison & McIntosh & Delicious \\
\hline $\begin{array}{c}\text { Time to half production vs. } \\
\text { rate of onset of production }\end{array}$ & -0.191 & -0.753 \\
$\begin{array}{c}\text { Rate of onset of production vs. } \\
\text { maximum production }\end{array}$ & 0.389 & 0.658 \\
$\begin{array}{c}\text { Time to half production vs. } \\
\text { maximum production }\end{array}$ & -0.206 & 0.232 \\
\hline
\end{tabular}

production data. Of the parameters describing the curves fitted to the data, the time to half production, which is a function of both time to first production and rate of onset of production, provided a good indicator of precocity. In addition, the plateau level of crop load was a good indicator of productivity.

Correlation between precocity and productivity. To assess whether there is a relationship among time of onset of production, rate of onset of production, and maximal productivity, correlation coefficients $(r$ ) were calculated for these parameters (Table 2). For 'McIntosh', all correlations were poor, while for 'Delicious', there was some correlation of rate of onset of production with the other two parameters but none between time to half production, which is an indicator of precocity, and maximal productivity.

A new method of assessing the effects of rootstocks on precocity andproductivity. The ability to separate precocity from productivity allows rootstock assessment to be based on the nature of the orchard system desired. Where the life of the orchard is to be short, precocity is the more important characteristic, while for longer lived orchard systems, mature productivity becomes more important. The lack of correlation between the two makes it important to determine both characteristics before making the assessment of rootstock performance.

\section{Literature Cited}

Crowe, A.C. 1975. Rootstock performance in Nova Scotia. Fruit Var. J. 29:36-37.

Cummins, J.N. and H.S. Aldwinckle. 1983. Breeding apple rootstocks, p. 294-384. In: J. Janick (ed.). Plant breedingreviews AVI Publ., Westport, Conn. 
Embree, C.G. and A.D. Crowe. 1986. The origin and development of the KSC apple rootstocks. Fruit Var. J. 40:116-120.

Embree, C.G., B.H. Lesser, and A.D. Crowe. 1993. Characterization of the Kentville Stock Clone apple rootstocks. I. Growth and Efficiency. J. Amer. Soc. Hort. Sci. 118:170-172.

Genstat 5 Committee. 1987. Genstat 5 reference manual. Oxford Univ. Press, New York.

Pearce, S.C. 1952. Studies in the measurement of apple trees. (1) The use of trunk girths to estimate tree size. Rpt. E. Malling Res. Sta. for 1951 p. 101-104.
Preston, A.P. 1967. Apple rootstock studies: Fifteen years results with some MIX crosses. J. Hort. Sci. 42:41-50

Schmidt, H. 1988. Criteria and procedures for evaluating apomictic rootstocks for apple. HortScience 23:112-114

Waring, J.H. 1920. The probable value of trunk circumference as adjustment to fruit yield in interpreting apple orchard experiments. Proc. Amer. Soc. Hort. Sci. 17:179-185.

Westwood, M.N. and A.N. Roberts. 1970. The relationship betweentrunk cross-sectional area and weight of apple trees. J. Amer. Soc. Hort. Sci. 95:28-30. 